\title{
Trustworthiness of Doctors from Public Health Campaigns
}

\author{
Jens Koed Madsen \\ University of Oxford \\ School of Geography and the environment \\ South Parks Road \\ OX1 3QY, Oxford, United Kingdom \\ Email: jens.madsen@ouce.ox.ac.uk \\ Phone number: 00447540318360 \\ Orcid: 0000-0003-2405-8496
}

\section{Acknowledgements}

The Danish Council of Independent Research has supported the research (ID: DFF - 132900021B). 


\begin{abstract}
Previous research concerning the effectiveness of public health campaigns have explored the impact of message design, message content, communication channel choice and other aspects of such campaigns. Meta analyses reported in the literature reveal, however, that the choice of endorsers in health campaigns remains unexplored. The present study addresses this gap in the literature by studying what makes doctors from public health campaigns appear trustworthy in the eyes of the receiver.

The present research examines propensity for trust as well facets of trustworthiness of such expert doctors based on a survey carried out in the UK (155 respondents). Underlying factors of trustworthiness are explored to gain more insight into the understanding of how trust may affect the public's belief updating and the formation of intentions. Exploratory factor analyses suggest four dimensions of trustworthiness. Multiple regression analyses demonstrate that these factors explain almost $70 \%$ of the variance in the participants' expressed trust in doctors from public health campaigns.

Doctors' ethical stance and their care for the health of the general population appear to be more important for perceived trustworthiness than their actual professional background, although their abilities and competences are closely related to ethics and benevolence. For policy makers this has important implications when selecting endorsers for public health campaigns in order to design effective health related communication, for example to combat obesity.
\end{abstract}

Keywords: Public health campaigns, trustworthiness, persuasion, doctors, endorsers 


\section{Introduction}

Studies demonstrate a current interest in obtaining deeper knowledge how to combat health problems. For example, as ten Have et al. (2012) points out, prevention of obesity is very high on the political public health agenda. Jebb et al. (2013) emphasize that a plethora of policies and actions may be launched to tackle such health problems. These might include legal steps, changing physical environments (e.g. building better biking lanes), financial and other incentives, or public health information campaigns.

Patchett et al. (2016) demonstrate how different countries emphasize legislation and regulation with regard to food and promotion strategies directed toward different groups, in particular educating children. The authors call for future research that focuses on how for example social marketing initiatives may improve individual's food choices. Such health campaigns may use creative strategies involving humor or fear (Mentazeri, McGee and McEwan 1998), but they may also be more strictly informative and attempt to change beliefs and eventually behaviour through evidence and argumentation - medical professionals often provide or accompany such information to lend credence to the evidence or argument. When this is the case, the choice of spokesmen/endorsers is extremely important. Snyder (2007) echoes this by noting that "to increase acceptance of the message, the campaign must select credible spokespeople and organizations that balance trustworthiness and expertise "(p. S37).

As demonstrated below, studies of the credibility of spokesmen or endorsers in public health campaigns represents a gap in the literature. Fundamentally, we do not know what constitutes a credible medical professional. If the targeted audience does not believe that an endorser is trustworthy the campaign will have little if any effect - this has been demonstrated in psychological literature on reasoning and decision-making (e.g. Harris et al., 2015; Madsen et al., 2019). That is, if the source appears credible, recipients of the message are more likely to revise their belief in the suggested direction as well as adapt the proposed action. If, however, the source is not seen as credible, belief revision can be contrary to suggestions (Madsen, 2016 shows that statements from distrusted political figures are not simply ignored, but decrease belief in the proposition) This has been described as the 'backfire effect' and has been demonstrated in several studies (e.g. Wood \& Porter, 2018). As such, understanding what makes endorses trustworthy is vital. The present article addresses this gap by examining the trustworthiness of medical endorsers (doctors) used in such public health campaigns. Through a factor analysis, we show that scores from Ethical behaviour, Benevolence and care 
for the population, and Competence predict expressed trust whilst Integrity and Propensity for trust, while positively correlated, do not.

In continuation of a meta-analysis reported by Snyder et al. (2004), Snyder (2007) reports evidence that health campaigns (e.g. their communication activities and channels, message content and presentation) may be able to change the dietary behaviour of selected audiences. Noar (2006) also finds evidence that health campaigns do have an effect on behaviour and beliefs, but that "Such impact can only be achieved, however, if principles of effective campaign design are carefully followed." (p. 21). Other articles have reported relevant research on this important issue. For example, Radtke et al. (2014) shows the effect of Compensatory Health Beliefs in generating intentions for adopting healthy behaviour, Erinosho et al. (2012) reports public awareness on the More Matters health campaign in the USA, and Bittner \& Kulesz (2015) report how social presence impacts food choices and healthy behaviour. Finally, Rekhy \& McConchie (2014) review the effect and designs of six health campaigns from various countries (including the UK, which is the country explored in the present paper).

Most of the campaigns reviewed targeted changes in attitudes, knowledge, or awareness as an integral part of a successful campaign. However, beliefs and intentions are often difficult to alter. Knox et al. (2013) report a study in which a sample of adults were presented various messages meant to change their beliefs about physical activity. One message was based on recommendations based on expert-derived guidelines, but a less precise message turned out to be more effective. The latter study is very central to the topic of the present study since we examine the trustworthiness of expert-doctors when they participate in health campaigns.

Doctors are frequently used in such campaigns as experts who convey various pieces of advice and information to the general public. This makes good sense since other sources of information may be seen as less reliable, as pointed out in recent articles. Stjerne et al. (2014) for example demonstrate that parents question the trustworthiness of food companies. In a similar vein Petersen et al. (2015) suggest that public servants may be alternatives since they may reconcile competing versions of 'truth'. Doctors may be seen as trustworthy if they represent high levels of experience and seniority (Paul et al., 2014) or empathy and caring (Fagerli et al., 2007). As demonstrated later, our empirical research points in the same direction. To our knowledge, however, it remains quite unexplored how the trustworthiness of doctors from public health campaigns is evaluated by the audience. 
Trustworthiness influences key aspects relevant for how to design a successful public health campaign. Trust in the endorser is an integral factor in the reception of persuasive messages (Petty \& Cacioppo, 1984; Tormala \& Clarkson, 2007; Chaiken \& Maheswaran, 1994) and in determining how convinced humans are of uncertain evidence from uncertain sources (Hahn et al., 2009; Harris et al., 2015). The perception of the source of a persuasive message has been identified as a key aspect of influence in terms of behaviour (Cialdini, 2009). Branching over the evidence cited in the above, then, there are strong reasons to assume that the trustworthiness of endorsing doctors in public health campaigns will be a key factor in persuading the population of the message, in securing compliance with the health advice given to the general population and with behavioural change in general.

This is the central research question raised in the present article. It is organised so that the concept of trustworthiness is initially presented. We then explain the materials and method used in our empirical study. After presenting the results of the study we consider future research avenues as well as implications for health communication.

\section{The Concept of Trustworthiness}

Given the interest in trustworthiness in several disciplines, it is hardly surprising that researchers have explored what makes a person appear trustworthy or not. Despite repeated attempts, however, different disciplines have generated different concepts of trustworthiness and thus no universal agreement has been reached. For example, trustworthiness has been described as a product of integrity, competence, fairness, and responsiveness to public needs (Citrin \& Muste, 1999), as being fair, equitable, honest, efficient, and responsive (Miller \& Listhaug, 1990), as character and competence (McCroskey \& Young, 1981; McCroskey, 1997). These definitions are reminiscent of findings in cognitive psychology where credibility has been defined as an amalgamation of trustworthiness and expertise (Bovens \& Hartmann, 2003; Hahn et al., 2009; 2012; Wang et al., 2011) and social psychological that defines credibility as a product of warmth and competence characteristics (see e.g. Fiske et al., 2007; Cuddy et al., 2011).

Most consistently, trustworthiness has been studied in management and leadership literature (Mayer et al., 1995; Mayer \& Davis, 1999; Mayer \& Gavin, 2005, see Colquitt et al., 2007 for a review). Here, trustworthiness is divided into three separate facets: benevolence, integrity, and ability. Benevolence is defined as “...the extent to which a trustee is believed to want to do good to the trustor", ability is "...that group of skills, competencies, 
and characteristics that allow a party to have influence within some domain", whilst integrity is "...the trustor's perception that the trustee adheres to a set of principles that the trustor finds acceptable" (all Mayer \& Davis, 1999, p. 124). These overall facets can plausibly encompass the common-sense facets offered in political science studies (such as 'fairness'). The findings from management studies function as the point of departure for the present research.

It is important to note the difference between the propensity for trust and facets of trustworthiness (see Colquitt et al., 2007). The former is a trait of the listener (how likely that person is to trust others) whilst the latter is a description of the speaker (what makes the person appear trustworthy). Trust propensity can thus be defined as "...a generalized expectancy that the verbal statements of others can be relied upon" (Rotter, 1967, p. 664), and we expect that a person with a high propensity for trust overall would have higher estimations of trust regardless of domain than someone who has a low propensity for trust. Propensity of trust can be measured via a scale developed in the literature (Kee \& Knox, 1970; Couch et al., 1996). If the identified facets of trustworthiness are appropriate, we predict a positive correlation between propensity for trust and predictions of trustworthiness. As Flores and Solomon puts it: "In the ideal case, one trusts someone because she is trustworthy, and one's trustworthiness inspires trust" (1998, p. 209).

\section{Materials and methods}

A total of 155 participants were recruited from a pool of social science students (e.g. psychology, marketing, and sociology) at universities in London. It is particularly interesting to study this age bracket (20-22 years old) since habits typically are formed at this age, laying the ground for possible health problems. This is stressed by Deshpande et al. (2009) who note that "Many food preferences are established early, but because people make more and more independent eating decisions as they move through adolescence," (p. 145). The empirical core of the present research is a survey attempting to capture respondents' propensity for trust as well as their perception of doctors' trustworthiness. The survey was written on the online survey-builder Qualtrics. There was no monetary incentive for completing the survey.

The indicators applied to measure trustworthiness take point of departure in 17 items reported in earlier studies to describe facets of trustworthiness (see Colquitt et al., 2007). In addition to the original 17 items, a number of items were generated for each category (benevolence, integrity, and capability) which were formulated more directly related to specific domains, here public health campaigns and characteristics of doctors participating in 
such campaigns. In total, 20 items were included in each category (60 in total). Propensity for trust was measured by the items suggested by Couch et al. (1996).

In accordance with previous studies, participants rated each item on a 5-point Likerttype scale ( 1 being 'disagree strongly' and 5 'agree strongly'). $25 \%$ of the items were reversescored. Participants first responded to the items pertaining to propensity for trust (all randomized) before responding to the 60 trustworthiness items (all randomized). Then, on a sliding scale from 0 to 100, participants indicated how much they trusted doctors from public health campaigns in general. This provides an observed trustworthiness score. Finally, participants provided information pertaining to their age, gender, and other demographical information.

In the following we explore the facets of trustworthiness. In addition to this, we examine whether the antecedents of trust (trustworthiness and trust propensity) are predictive of respondents' own perception of trust in doctors that participate in health campaigns.

\section{Results}

An exploratory factor analysis with Varimax rotation (SPSS 20.0) was carried out to identify factors of trustworthiness. All 60 items were included in the analysis, as Bartlett's test of sphericity $(<0.001)$ and the Kaiser-Meyer-Olkin measure of sampling adequacy $(0.913)$ both suggest that the full data set was adequate for factor analysis.

Upon examining the initial factor analysis, Eigen-values less than 1 suggests extracting 14 factors, which is far too much regarding interpretive potential. Since this is an exploratory study a process of reducing complexity in terms of number of items was therefore established. Consecutive factor analyses limited the number of items. Following each analysis, items that loaded $<0.5$ were discarded from the analysis. Three analyses were conducted (Bartlett's tests and KMO measures show that all samples were adequate for analyses). Having followed the principles described in the above, the fourth factor analysis $($ sphericity $<0.001, \mathrm{KMO}=0.925)$ provided a list of 28 items distributed across four factors, which account for $57.275 \%$ of the variance.

Table 1 exhibits how the remaining 28 items load on each of the four extracted factors (all loadings less than .5 have been suppressed). The items loading on the first factor all revolve around doctors' attitude and behaviour concerning general health in the population. We therefore label this factor 'Benevolence and care for the population'. A summated scale comprising all 10 items shows high internal consistency (a Cronbach's Alpha $=0.903$ ). 
Accordingly, the second factor is labelled 'Ethical behaviour' (Cronbach's Alpha for a summated scale of the five items $=0.820)$. The third factor we call 'Integrity ' $(\alpha=0.831)$, and the fourth factor 'Competence' ( $\alpha=0.819)$. 
Table 1. Factor analysis of complete set of items (UK)

Rotated Component Matrix ${ }^{a}$

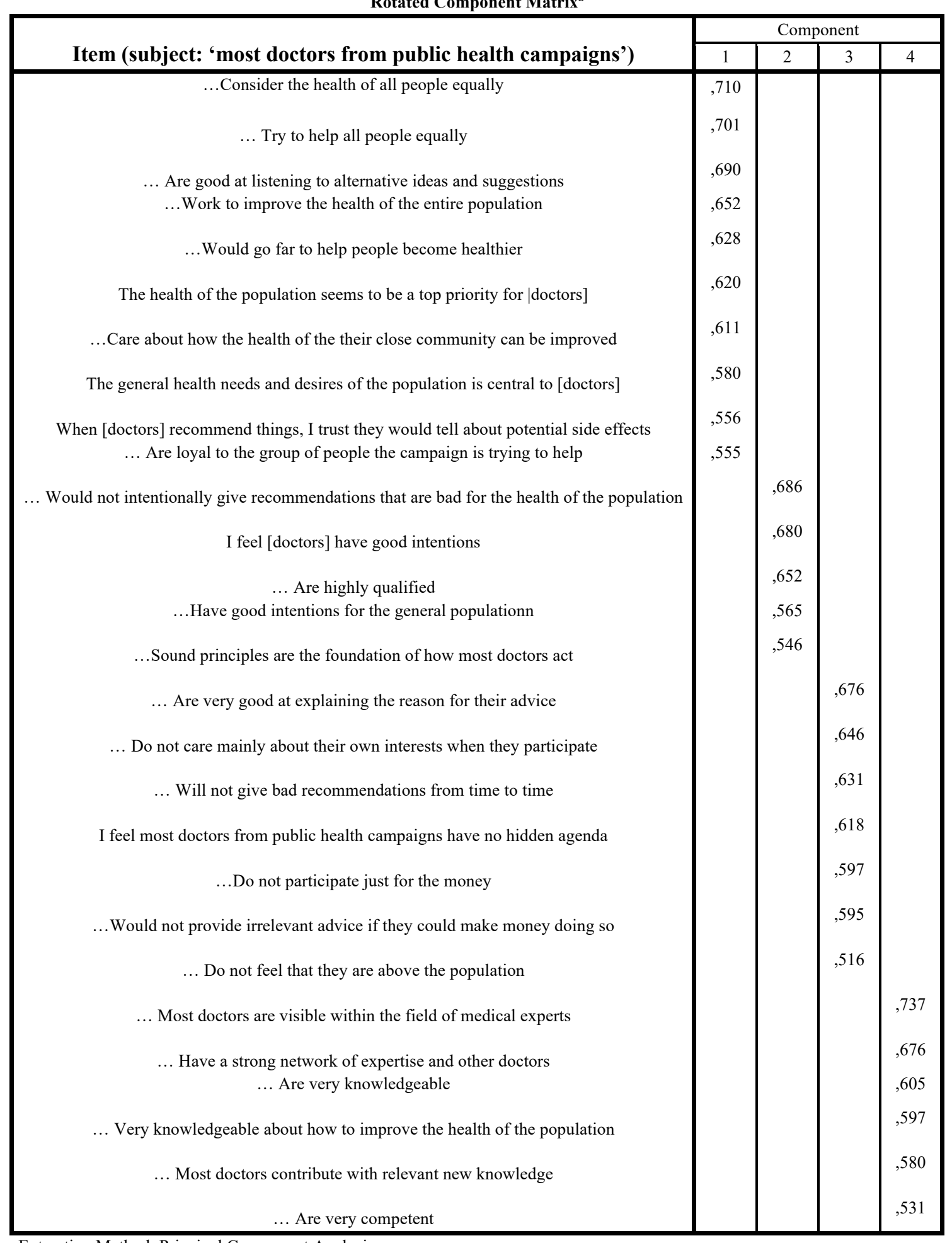

Extraction Method: Principal Component Analysis.

Rotation Method: Varimax with Kaiser Normalization. ${ }^{a}$

a. Rotation converged in 7 iterations. 
It is obvious that the original facets of benevolence, integrity, and ability (Colquitt et al., 2007) are reflected also in these domain specific factors, but the 'ability' factor seems to be closely related to 'Ethical behaviour' as well as 'competence' since both of these encompass items related to qualifications and knowledge. Similarly, 'benevolence' is visible in 'Benevolence and care for the population' as well as 'Ethical behaviour'. This indicates that respondents perceive the ability and the values of doctors to be highly intertwined.

\section{Predicting likelihood of trust from antecedents}

As argued in Colquitt et al. (2007), trust propensity (see Couch et al., 1996) and factors of trustworthiness are both antecedents to trust. In the following, the summated scales calculated on the basis of each of the four factors (as explained above) as well as the participant's trust propensity score will be used as independent variables in a stepwise multiple regression analysis in which the dependent variable is the respondent's trust expressed in doctors participating in health campaigns (measured on a sliding scale from 0 (do not at all trust) to 100 (complete trust). Respondents expressed fairly high levels of trust in doctors participating in health campaigns (average $=59.70)$.

The analysis shows that Ethical behaviour, Benevolence and care for the population, and Competence, all contribute significantly to explain trust in doctors (see table 2). In all, the summated scales (based on the three factors) account for $68.6 \%$ of the observed variance of expressed trust.

Table 2: Predicting likelihood of trust (step-wise multiple regression)

\begin{tabular}{|l|l|l|l|}
\hline Factor & Adjusted $\mathbf{R}^{2}$ & F change & Sig. F change \\
\hline Ethical behaviour & .577 & 211.280 & $<0.001$ \\
\hline $\begin{array}{l}\text { Benevolence and care for the } \\
\text { population }\end{array}$ & .668 & 42.688 & $<0.001$ \\
\hline Competence & .686 & 10.057 & 0.002 \\
\hline
\end{tabular}

In the final model, including all three factors, the constant is -42.93 , and the regression coefficient (B-values) is 12.11 for 'Ethical behaviour, 10.98 for 'Benevolence and care for the population ', and 7.09 for 'Competence. 'Integrity' and 'Propensity for trust' were not significant. 


\section{Discussion}

As trustworthiness has been show to influence a range of relevant aspects from belief changes (Harris et al., 2015) to eventual compliance with recommendations and public policy (Ayres \& Braithwaite, 1992), it is imperative to know what constitutes trustworthy doctors in order to create successful health campaigns. If the doctors who endorse certain advice are not credibly perceived as trustworthy, we should expect their advice to be less persuasive, be less efficient in changing attitudes, and have less impact in getting the general public to comply with their advice.

The scores from Ethical behaviour, Benevolence and care for the population, and Competence are predictive of expressed trust whilst Integrity and Propensity for trust correlated positively, but were not significant. Ethical behaviour was the factor that accounted for most of the expressed trust in the survey. Items related to ethics included the ethical manner by which the doctor act (e.g. "would not intentionally give recommendations that are bad for the health of the population" and "sound principles are the foundation of how most doctors act"), but this is intertwined with abilities since these doctors are perceive to be ("highly qualified"). Thus, the important aspects of the ethical stance of British doctors are action- and ability-based. Competence was concerned with the manner by which the doctor contributed to his or her field (e.g. "Most doctors are visible within the field of medical experts" and "Most doctors contribute with relevant new knowledge"). Finally, the factor Benevolence and care for the population comprises helping people equally and with compassion. The findings suggest that concepts identified in management studies such as ability, benevolence, and integrity are central, as items from these categories are found also in the factors identified here. As mentioned, however, our results indicate that for example ability is strongly intertwined with values and ethics of doctors.

\section{Concluding remarks}

The study suggests that participants are highly concerned with whether or not doctors from public health campaigns are trustworthy or not. Asked directly, participants clearly responded that it is important that doctors from public health campaigns are trustworthy (mean $=78.26$ on a scale from 0-100). Given the reported desire and need for trustworthy doctors, it is imperative to select the most trustworthy endorsing source (here doctor) when designing a public health campaign aiming at for example reducing obesity. This is the first implication based on the results of this study. 
Misplaced presentations of the expert sources connected with the campaign may lead to decrease in persuasive potential and less compliance with the advice given. The perception of trustworthiness of the doctors from public health campaigns may be central to the manner by which the evidence and advice is perceived, whether or not the target audience changes attitudes towards the messages, and whether or not the population complies with the advice.

The second implication of the present research is that it is important to select doctors that have high ethical standards and are known for caring for the health of the general population. This seems to be equally important as the actual professional background of the endorsing doctor which is an interesting result. Respondents find higher trustworthiness to be connected to aspect related to doctors' ethical and altruistic qualities. Clearly, this indicates the considerations that policy makers and campaign designers have to go through carefully. It is of utmost importance to choose the 'right' doctor or expert so that the receivers can have trust in the advice given, which increases the likelihood that the audience will comply with the advice.

Trust in experts connected with public health campaigns is central to the success of the campaigns. The present research is only a first step to obtain more knowledge about how to design better health campaigns, but it provides valuable insight into criteria for selecting endorsing doctors. It has yet to be explored how the trustworthiness of doctors may concretely advance or maybe hinder change in beliefs or behaviour.

The study has some limitations that future research may address. First of all the respondents are students. It would clearly be fruitful to carry out a study among the general population since students cannot be seen as representative for the population. Another limitation of the study is its exploratory character. An important aim was to examine the extent to which trustworthiness scales used in other domains were applicable. Based on this research a set of items have been developed which may be applied in future studies and thus tested further. The present study is confined to the UK. Obviously, empirical studies in other countries are necessary to reach more generalizable results.

The current research also points to some interesting methodological avenues of future research in public health campaigns as well as in the psychology of reasoning and argumentation. For public health campaigns, it would be prudent to conduct experimental studies in which participants between groups received health advice from doctors from public health campaigns that differed in types of trustworthiness. Potentially, such studies should also collect individual data regarding educational background, personality traits, and previous beliefs regarding the communicated health advice. This would allow for a more fine-grained 
understanding of the kinds of sources and point towards a micro-managed style of efficient campaigns that could be implemented differently depending on the target audience.

Our study strongly indicates that trust in experts connected with public health campaigns is central to the success of the campaigns. It is imperative that we appreciate the make-up of what makes these people appear trustworthy to the target population. The current study provides an initial indication of how to understand and predict trust in public health campaigns, but additional studies are warranted to probe deeper into the effect and influence of different experts in campaigns. 


\section{References}

Ayres, I. \& Braithwaite, J. (1992) Responsive Regulation, Oxford University Press

Bittner, J. V. \& Kulesz, M. M. (2015) Health promotion messages: The role of social presence for food choices, Appetite 87, 336-343

Bovens, L., \& Hartmann, S. (2003). Bayesian epistemology. Oxford: Oxford University Press.

Chaiken, S. \& Maheswaran, D. (1994) Heuristic Processing Can Bias Systematic Processing: Effects of Source Credibility, Argument Ambiguity, and Task Importance on Attitude Judgement, Journal of Personality and Social Psychology 66 (3), 460-473

Cialdini, R. B. (2009) Influence: The Psychology of Persuasion, Collins Business

Citrin, J. \& Muste, C. (1999) Trust in government, in Robinson, J. P., Shaver, P. R., Wrightsman, L. S. (Eds.) Measures of political attitudes: Measures of social psychological attitudes, Vol. 2. (pp. 465-532), San Diego, CA, US: Academic Press.

Colquitt, J. A., Scott, B. A. \& LePine, J. A. (2007) Trust, Trustworthiness, and Trust Propensity: A Meta-Analytic Test of Their Unique Relationships With Risk Taking and Job Performance, Journal of Applied Psychology 92 (4), 909-927

Couch, L. L., Adams, J. M. \& Jones, W. H. (1996) The Assessment of Trust Orientation, Journal of Personality Assessment 67 (2), 305-323

Cuddy, A. J. C., Glick, P. \& Beninger, A. (2011) The dynamics of warmth and competence judgments, and their outcomes in organizations, Research in Organizational Behavior 31, 73 98

Deshpande, S., Basil, M.D. \& Basil, D. Z. (2009) Factors Influencing Healthy Eating Habits Among College Students: An Application of the Health Belief Model, Health Marketing Quarterly, 26 (2), 145-164, 
Erinosho, T. O., Moser, R. P., Oh, A. Y., Nebeling, L. C. \& Yaroch, A. L. (2012) Awareness of the Fruits and Veggies-More Matters campaign, knowledge of the fruit and vegetable recommendation, and fruit and vegetable intake of adults in the 2007 Food Attitudes and Behaviors (FAB) Survey, Appetite 59, 155-160

Fiske, Susan T., Cuddy, A. J. C. \& Click, P. (2007) Universal dimensions of social cognition: warmth and competence, Trends in Cognitive Sciences 11 (2), 77-83

Flores, F. \& Solomon, R. C. (1998) Creating trust, Business Ethics Quarterly 8, 205-232

Hahn, U., Harris, A. J. L., \& Corner, A. (2009) Argument content and argument source: An exploration, Informal Logic 29, 337-367

Hahn, U., Oaksford, M., \& Harris, A. J. L. (2012) Testimony and argument: A Bayesian perspective. In F. Zenker (Ed.), Bayesian Argumentation (pp. 15-38). Dordrecht: Springer.

Harris, A.J.L., Hahn, U., Madsen, J. K. \& Hsu, A. (2015) The Appeal to Expert Opinion: Quantitative support for a Bayesian Network Approach, Cognitive Science 40, 1496-1533

Heijens T, Janssens W, Streukens S. (2011) The effect of history of teasing on body dissatisfaction and intention to eat healthy in overweight and obese subjects. European Journal of Public Health, 22, 1, 121-126

Jebb S.A., Aveyard P.N., Hawkes C. The evolution of policy and actions to tackle obesity in England. Obesity reviews, 14 (suppl. 2), 2013: $42-59$.

Kee, H. W. \& Knox, R. E. (1970) Conceptual and methodological considerations in the study of trust and suspicion, Journal of Conflict Resolution 14, 357-366

Knox E.C.L., Webb O.J., Esliger D.W., Biddle S.J.H., Sherar L.B. Using threshold messages to promote physical activity: implications for public perceptions of health effects. European Journal of Public Health, Vol. 24, No. 2, 2013: 195-199. 
Madsen, J. K. (2016) Trump supported it?! A Bayesian source credibility model applied to appeals to specific American presidential candidates' opinions, Papafragou, A., Grodner, D., Mirman, D., \& Trueswell, J.C. (Eds.) Proceedings of the 38th Annual Conference of the Cognitive Science Society, Austin, TX: Cognitive Science Society, 165-170

Madsen, J. K., Hahn, U. \& Pilditch, T. (2019) Reasoning about dissent: Expert disagreement and shared backgrounds, Proceedings of the $41^{\text {st }}$ Annual Conference of the Cognitive Science Society, 2235-2242

Mayer, R. C., Davis, J. H. \& Schoorman, F. D. (1995) An integrative model of organizational trust, Academy of Management Review 20, 709-734

Mayer, R. C. \& Davis, J. H. (1999) The effect of the performance appraisal system on trust for management: A field quasi-experiment, Journal of Applied Psychology 84, 123-136

Mayer, R. C., \& Gavin, M. B. (2005) Trust in management and performance: Who minds the shop while the employees watch the boss? Academy of Management Journal 48, 874-888

McCroskey, J. C. (1997) Ethos: A Dominant Factor in Rhetorical Communication, in McCroskey, J. C. (Ed.) An Introduction to Rhetorical Communication (7th ed.), Allyn and Bacon, 87-107

McCroskey, J. C. \& Young, T. J. (1981) Ethos and Credibility: The Construct and its Measurement After Three Decades, The Central Speech Journal 32, 24-34

Mentazari, A, S. McGee and J. McEwan (1998) Fear-inducing and positive image strategies in health education campaigns, International Journal of Health Promotion and Education 36 (3), 68-75

Miller, A. \& Listhaug, O. (1990) Political performance and institutional trust, in Norris, P. (Ed.) Critical Citizens: Global Confidence in Democratic Government (pp. 204-216), Oxford, UK: Oxford University Press 
Noar, S. M. (2006) A 10-Year Retrospective of Research in Health Mass Media Campaigns: Where Do We Go From Here?, Journal of Health Communication 11, 21-42,

Patchett A., Yeatman H.R., Johnson K.M. (2016) Obesity framing for health policy development in Australia, France and Switzerland. Health Promotion International 31, 83-92

Petty, R. E. \& Cacioppo, J. T. (1984) Source Factors and the Elaboration Likelihood Model of Persuasion, Advances in Consumer Research 11, 668-672

Radtke, T., Kaklamanou, D., Scholz, U., Hornung, R. Armitage, C. J. (2014) Are diet-specific compensatory health beliefs predictive of dieting intentions and behaviour? Appetite 76, 3643

Rekhy, R. \& McConchie, R. (2014) Promoting consumption of fruit and vegetables for better health. Have campaigns delivered on the goals? Appetite 79, 113-123

Rotter, J. R. (1967) A new scale for the measurement of interpersonal trust, Journal of Personality 35 (4), 651-665

Snyder, L.B. (2007) Health Communication Campaigns and Their Impact on Behavior, Journal of Nutrition, Education and Behavior 39, 32-S40

Snyder, L.B., Hamilton, M.A., Mitchell, E.W., Kiwanuka-tondo, J., Fleming-Milici, F, Proctor, D. \& John, R.W. (2004) A Meta-Analysis of the Effect of Mediated Health Communication Campaigns on Behavior Change in the United States A Meta-Analysis of the Effect of Mediated Health Communication Campaigns on Behavior Change in the United States, Journal of Health Communication 9, 71-96

Tormala, Z. L. \& Clarkson, J. J. (2007) Assimilation and Contrast in Persuasion: The Effect of Source Credibility in Multiple Message Situations, Personality and Social Psychology Bulletin 33 (4), 559-571 
van Have M., van der Heide A., Mackenbach J.P., de Beaufort I.Z. An ethical framework for the prevention of overweight and obesity: a tool for thinking through a programme's ethical aspects. European Journal of Public Health, Vol. 23, No. 2, 2012: 299-305

Wang, D., Abdelzaher, T., Ahmadi, H., Pasternack, J., Roth, D., Gupta, M. \& Aggarwal, C. (2011) On Bayesian interpretation of fact-finding in information networks, in 14th International Conference on Information Fusion (Fusion 2011)

Wood, T. \& Porter, E. (2018) The elusive backfire effect: Mass attitudes' steadfast factual adherence, Political Behavior 1-26 